\title{
O mundo da comunicação e o mundo da criança
}

\author{
Ariane Porto Costa Rimoli \\ Pós-doutora em Comunicações e Artes na ECA-USP e Professora do Instituto de Artes \\ da UNICAMP. Sócia Fundadora da TAO Produções Artísticas e consultora do Programa \\ das Nações Unidas para o Desenvolvimento. \\ E-mail: chrizcb@gmail.com
}

Resumo: Pensar a criança na contemporaneidade é compreendê-la como um ser social que interage dinamicamente na sociedade, influenciando e sendo influenciada por ela, produzindo e sendo produzida por suas relações. Relações essas que passam pela interação com as diferentes mídias. A mídia se apresenta como o espaço privilegiado para os diálogos e monólogos acerca da infância e juventude, e também para as próprias crianças refletirem sobre a sociedade e seu espaço/representação nela. Dessa forma, se faz necessário refletir sobre como o mundo da comunicação e o mundo da criança se convergem, e quais relações, significados e vivências emergem dessa confluência.

Palavras-chave: criança; comunicação; educomunicação; mídias; sociedade.
Abstract: Thinking children in contemporary society is to understand them as a social being dynamically interacting in society, influencing and being influenced by it, producing and being produced by their relations. These relationships go through interaction with different media. The media presents itself as a privileged space for dialogue and monologues about the childhood and youth, and also a space to the children themselves think about the society and their environment/representation in it. Thus, it is necessary to reflect on how the world of communication and the world of the child converge, and what relationships, meanings and experiences emerge from this confluence.

Keywords: child; communication; educommunication; media; society.

\section{INTRODUÇÃO}

Pensar a criança hoje não é apenas considerar sua faixa etária ou seu amadurecimento, tampouco é imaginá-la desconectada da sociedade — um "ser" à parte, alheio a tudo que o cerca. Pensar a criança hoje é considerá-la um ser social, plenamente integrado a seu meio, influenciando e sendo influenciada por ele. Como afirma Pacheco,

[...] conhecer a criança é pensá-la não apenas numa perspectiva evolutiva e etária; é compreendê-la como ser social, determinado historicamente, interagindo dinamicamente, influenciando e sendo influenciada. É, sobretudo, pensá-la como um ser produto e produtor das relações que ocorrem na família, na sociedade, na comunidade. Essas relações passam pela interação com as diferentes mídias ${ }^{1}$.

Recebido: 22/03/2015

Aprovado: 29/06/2015

1. PACHECO, E. D. (org.). Televisão, criança e imaginário. São Paulo: Papirus, 1998. 
E fazer esse exercício de reflexão exige um olhar crítico sobre suas experiências sociais, dia a dia mais complexas. Numa sociedade cada vez mais permeada pelas mídias e por suas tecnologias, as crianças convivem diariamente com suas imagens, tecendo novas experiências e novas formas de perceber o mundo e a si próprias.

E a Comunicação? A Comunicação nos permite sempre transformar novos conceitos em palavras novas. Conceitos que muitas vezes já eram praticados há muito tempo por muitos e em muitos lugares/tempos distintos. E que uma vez codificados em palavras/conceitos, passam a unir, a criar redes e estabelecer relações. A educação é comunicação que transforma e move e torna a transformar, conduzindo sempre a direções várias. Não existe sentido único, caminho sem atalhos, sem encruzilhadas. É assim com a educomunicação.

Dessa forma, torna-se imprescindível refletir sobre a relação entre esses dois mundos: o mundo da comunicação e o mundo da criança, que se convergem e se permeiam, criando novos significados e vivências.

\section{A EDUCAÇÃO E A COMUNICAÇÃO: EDUCOMUNICAÇÃO}

A Educomunicação é entendida como

o conjunto das ações inerentes ao planejamento, implementação e avaliação de processos, programas e produtos destinados a criar e a fortalecer ecossistemas comunicativos em espaços educativos presenciais ou virtuais, assim como a melhorar o coeficiente comunicativo das ações educativas, incluindo as relacionadas ao uso dos recursos da informação no processo de aprendizagem² ${ }^{2}$.

Na verdade, ganha notoriedade o número de estudos acadêmicos que vem sendo desenvolvidos na Escola de Comunicações e Artes da Universidade de São Paulo (ECA-USP) na linha de pesquisa que inter-relaciona a Comunicação e a Educação. Informações da Biblioteca da ECA dão conta de que mais de 65 dissertações ou teses sobre essa inter-relação foram defendidas desde o ano 2000. Merece destaque, entre os trabalhos, a tese de Genésio Zeferino Silva Filho, intitulada Educomunicação e sua metodologia: um estudo a partir de práticas de ONGs no Brasil, defendida em 2004. A pesquisa teve como foco a identificação de práticas educomunicativas desenvolvidas em ONGs em todo o Brasil.

Esses trabalhos desenvolvidos na ECA e em outras universidades brasileiras

2. SOARES, Ismar de Oliveira. Caminhos da educomunicação na América Latina e nos Estados Unidos. In: SOARES, Ismar de Oliveira (org.). Cadernos de Educomunicação 1: Caminhos da Educomunicação. São Paulo: Editora Salesiana, 2003, p. 43. e do exterior vêm contribuindo para a consolidação do campo da Educomunicação, oferecendo aos profissionais da Comunicação e da Educação bases para reflexões epistemológicas e práticas educativas.

\section{MÍDIA E ESCOLA}

A escola e a mídia dividem e disputam passo a passo a atenção e a dedicação de crianças e adolescentes ao mesmo tempo em que ambas atuam na 
formação e informação dos pequenos interlocutores. Tanto os meios massivos de comunicação - em especial a televisão e a internet - quanto a escola, produzem conteúdos e os disponibilizam para as crianças. Com algumas diferenças importantes: os meios de comunicação não cobram retorno do que foi ensinado/aprendido e não punem quando a criança não atinge as metas mínimas nas avaliações.

E como "pais divorciados", ambas as partes "desmerecem" o perfil do outro: a Escola é antiquada, enquanto a Mídia é irresponsável. A Escola ensina conteúdos inúteis, e a Mídia promove comportamentos inadequados e violentos. E poderíamos seguir com uma longa lista de acusações. Não menos extensas são as listas dos projetos e pesquisas produzidas ao longo das últimas décadas que buscam definir as áreas de conflito, ao mesmo tempo que apontam possibilidades de reconciliação.

Nas últimas décadas, várias parcerias entre instituições governamentais, educativas, emissoras de televisão e produtoras de conteúdo vêm se estabelecendo para a o desenvolvimento de projetos de maior ou menor impacto e abrangência, que buscam unir educação e comunicação.

Os conteúdos presentes nas programações televisivas e as metodologias de ensino tradicionais adotadas pela Escola não são nem alteradas nem levadas em consideração enquanto potenciais agentes no processo. Ou seja: as produções "politicamente incorretas" - com excesso de violência e sexo — veiculadas pelos canais de televisão, e a figura tradicional do professor munido de giz, livros, provas e notas, ainda resistem.

Segundo afirmação de Ismar de Oliveira Soares na Third World Summit on Media for Children realizada em Tessalônica, Grécia, em 2001, mais importante do que a avaliação dos impactos negativos dos conteúdos (violentos ou sexistas) sobre o público infantil, deveria ser a garantia dos direitos das crianças em expressar-se por meio dos meios de comunicação, instrumentos que deveriam ser incorporados pela educação. Esse ponto, contudo, tem se mostrado o "calcanhar de Aquiles".

Para Maria Aparecida Baccega, a escola, enquanto instituição viva se transforma e adquire novos significados constantemente, e o discurso dos meios de comunicação está presente em seus domínios, porém, de forma desajustada. Para corrigir tal descompasso, decorrente da não incorporação das novas linguagens, ela aponta: "é preciso entender que essas novas mediações são constitutivas de outra cultura, a cultura que tem as tecnologias como mediadoras"3.

Mas para isso, várias barreiras e preconceitos precisam ser superados. Antes de pensarmos que a estrutura formal e o currículo precisam ser transformados para incorporar tais alterações, é importante levar em consideração a necessidade de mudança na base. Para Cristina Costa, é necessário que a educação formal reveja seus paradigmas letrados, herança de uma cultura eurocentrada, iluminista e burguesa que teve na escrita a base de produção e controle do conhecimento. Só dessa forma poderá romper as barreiras que a separam da cultura globalizada,
3. BACCEGA, Maria Aparecida. Televisão e Escola: uma mediação possível? São Paulo: Senac, 2003, p. 62. 
massiva, baseada em múltiplas linguagens e tecnologias de comunicação, contexto no qual se afirmam os meios audiovisuais ${ }^{4}$.

\section{UNIDOS EM CONFLITO}

Estabelecendo uma mediação entre as instituições — Família, Escola, Igreja, Estado - , a mídia se apresenta como o espaço privilegiado para os diálogos e monólogos acerca da infância e juventude. Porém, essa mediação, ao mesmo tempo em que é aceita, é contestada:

As mídias estão envolvidas nisso de formas contraditórias. De um lado, elas são o veículo primordial em que se travam os debates correntes sobre a natureza em mutação da infância - e nesse processo, sem dúvida, contribuem para o crescente sentimento de medo e pânico. De outro lado, no entanto, as mídias são frequentemente acusadas de ser as causas originárias de tais problemas - de provocar indisciplina e comportamentos agressivos, de inflamar a sexualidade precoce e de destruir os laços sociais saudáveis que poderiam prevenir sua ocorrência ${ }^{5}$.

A influência da Escola de Frankfurt foi decisiva para toda uma geração que se formou sob a certeza de que os meios de comunicação atuam como instrumentos de controle social, manipulação e alienação. Ainda hoje, pesquisas são feitas para demonstrar a crescente importância da televisão no cotidiano das crianças e os impactos negativos das temáticas e formatos das produções às quais elas têm acesso. Além dos efeitos da programação "inadequada" destinada ao público infantil, tem sido grande a preocupação com a publicidade sobre a saúde física e mental das crianças.

A responsabilidade da mídia é também atribuída pela sua influência na formação de pequenos consumidores, ao mesmo tempo em que constrói pequenos objetos de consumo. A "culpa" da mídia pela "comercialização da infância" convive com a "culpa" dos governos pela ineficiência na regulamentação de corporações comerciais.

4. COSTA, Cristina. Educação, imagem e mídias. São Paulo: Cortez, 2005, p. 21.

5. BUCKINGHAM, David. Crescer na era das mídias eletrônicas. São Paulo: Loyola, p. 16.

6. Apud DEL PRIORE, Mary. História das crianças no Brasil. São Paulo: Contexto, 1999.

7. BAKAN, Joel. Crianças e o mundo corporativo. In: CAVOUKIAN, Faffi et al. Honrar a criança: como transformar esse mundo. São Paulo: Instituto Alana, 2009, p. 250.
Segundo Susan Linn,

Do momento em que acordam até a hora de dormir, elas são assoladas com o ruído da mídia comercializada e das coisas que ela vende. [...] Em 1983, as empresas gastavam US\$ 100 milhões por ano em propaganda direta para as crianças. Hoje elas gastam US\$ 15 bilhões. Hoje, enormes conglomerados de mídia possuem canais de televisão, estações de rádio, empresas de internet e estúdios de cinema. [...] Se as crianças vivenciam apenas o mundo como é moldado para a cultura de consumo - se têm pouca ou nenhuma oportunidade de ter outra experiência - como vão desenvolver os valores e identidade necessários para resistir às mensagens comerciais ${ }^{6}$ ?

Para Joel Bakan ${ }^{7}$, as toxinas mentais presentes nos 30 mil comerciais de televisão por ano que uma criança assiste em média, são tão prejudiciais à saúde quanto as toxinas químicas presentes nos produtos que elas consomem, estimuladas pela mesma publicidade. Entenda-se por danos à saúde tanto os 
problemas causados pela crescente obesidade e diabetes infantil quanto os problemas sociais e mentais provocados supostamente pela programação inadequada, com alto índice de violência e comportamentos sexuais precoces. A mídia é então acusada dos prejuízos à formação de cidadãos saudáveis, física e socialmente adequados.

\section{ESTABELECENDO MEDIAÇÕES}

Os pressupostos que norteiam diferentes linhas de análises sobre o tema infância e mídias sugerem que a noção de infância seja em si uma construção social, histórica, e que a cultura e a representação - também sob a forma das mídias eletrônicas - sejam uma das principais arenas em que essa construção é desenvolvida e sustentada. [...] O significado de infância está sujeito a um constante processo de luta e negociação, tanto no discurso público (por exemplo, na mídia, na academia ou nas políticas públicas) como nas relações pessoais, entre colegas e familiares ${ }^{8}$.

A infância é uma construção social intimamente ligada a outra categoria socialmente definida - a idade adulta — e as mediações extrapolam os espaços privados e se realizam no espaço público criado pela mídia. E é nesse espaço que a sociedade dialoga e busca, em sua esquizofrenia crônica, culpados pela inadequação das relações entre crianças/adultos, crianças/crianças, adultos/ adultos.

A mídia é o "meio" onde são veiculadas programações que exaltam ora a figura do adulto-criança, ora a figura da criança-adulto, enaltecendo as características positivas do adulto puro, ingênuo e essencialmente bom, e da criança responsável, ponderada e independente. Essas programações, engendradas em diferentes esferas, respondem a demandas em constante mutação. A mídia é o instrumento reprodutor, um meio tecnológico para a expressão de vozes conflitantes de uma sociedade que separa a criança da infância e que adota critérios e definições diferenciadas para cada uma, de acordo com interesses que se alternam.

Mas não é algo novo. A mídia veio substituir os já tradicionais meios de difusão de vozes das mesmas partes da sociedade.

Foi a voz dos adultos que registrou, ou calou, sobre a existência dos pequenos, possibilitando ao historiador escrutar esse passado utilizando seus registros e entonações: seja por meio das cartas jesuíticas relatando o esforço de catequese e normatização de crianças indígenas ou a correspondência das autoridades coloniais sobre a vida nas ruas, pano de fundo para as crianças mulatas e escravas. Seja por meio das narrativas dos viajantes estrangeiros, os textos de sanitaristas e de educadores, os códigos de menores, os jornais anarquistas, os censos do IBGE etc. O que restou da voz dos pequenos ${ }^{9}$ ?

Continuamos a escutar vozes adultas de uma sociedade que, em busca de culpados pelos seus atos, transforma a mídia em um ser com vontade própria. 8. BUCKINGHAM, David,
op. cit.
9. DEL PRIORE, Mary,
op. cit. 
10.ROSA, Guimarães. Grande Sertão: Veredas. Rio de Janeiro: José Olympio, 1979.

11. OROZCO GÓMEZ, Guillermo. Mediações e televisão pública: A desconstrução múltipla da televidência na era da vassalagem mediática. In: RINCÓN, Omar. Televisão pública: Do consumidor ao cidadão. São Paulo: Fundação Friedrich Ebert 2002.

12. MARTÍN-BARBERO, Jesús. Ensanchando territórios en comunicación/ educación. In: VALDERRAMA, Carlos. Comunicación \& Educación. Bogotá: Universidad Central, 2000 .

13. Idem. La Comunicación desde la Comunicación. Buenos Aires: Grupo Editorial Norma, 2002.
Um demiurgo. Mas, segundo Guimarães Rosa, mesmo o "diabo vige dentro do homem, os crespos do homem - ou é o homem arruinado, ou o homem dos avessos. Solto, por si, cidadão, é que não tem diabo nenhum"10.

Guillermo Orozco avalia que a principal contribuição latino-americana sobre mídia e crianças no campo da investigação comunicativa tem sido a conceitualização das "mediações" e das "práticas e estratégias" comunicativas das audiências ${ }^{11}$.

Investigadores latino-americanos como o próprio Orozco e Jesús Martín-Barbero ${ }^{12,13}$ buscam detectar e analisar - baseando-se na teoria da recepção - as mediações individuais, situacionais, institucionais e tecnológicas que determinam as diferentes apropriações que fazem os adolescentes das mensagens da televisão. Nesse sentido, as avaliações se tornam mais complexas, já que entram em jogo outros fatores que alteram os significados das mensagens desde o momento em que são produzidas até o momento em que são recebidas pelos diversos públicos.

\section{CÚPULAS MUNDIAIS DE MÍDIA PARA CRIANÇAS E ADOLESCENTES}

Um exemplo de como a sociedade, incluindo as crianças e adolescentes, pode desempenhar um papel mais importante nessas questões são as Cúpulas Mundiais de Mídia para Crianças e Adolescentes. Esse espaço, criado na Austrália, em 1995, oferece uma plataforma global para discussões sobre o papel da mídia para crianças na atualidade. Desde então, são realizadas Cúpulas Mundiais a cada três anos.

Entre os principais objetivos da iniciativa estão conseguir maior compreensão da evolução dos meios de comunicação e suas interfaces com as crianças em todo o mundo, levantando as diversas realidades e promovendo princípios orientadores para as relações dos meios com o público infantil. Nesse sentido, os meios de comunicação, ao lado de seu caráter nocivo e prejudicial, são também entendidos como indutores da democracia, dos direitos humanos e do desenvolvimento sustentável.

Após ser realizada na Austrália, Inglaterra, Grécia, Brasil e África, a Sexta Cúpula foi realizada em Karlstad, na Suécia, entre os dias 14 e 18 de junho de 2010. Adultos e jovens de diversas partes do mundo discutiram como deve ser a mídia voltada para o público infanto-juvenil e o que precisa ser feito para aumentar as produções de mídia pelos jovens. Porém, a grande novidade do evento foi a criação do Conselho Global de Juventude e Mídia - Global Youth Media Council (GYMC). Um grupo formado inicialmente por vinte jovens de 13 a 24 anos, sistematizou questões e recomendações para conduzirem um debate que deve ter continuidade após o encerramento do evento.

As recomendações abordam temas como segurança na internet; representatividade negativa de crianças, adolescentes e jovens nos meios de comunicação; 
responsabilidade social da mídia, além do acesso, produção e difusão de mídia jovem. Ações de advocacy pelo direito à comunicação também foram colocadas no documento.

Relacionamos abaixo as questões e recomendações do GYMC:

1. Acesso limitado à internet: Os governos, operadoras de telefonia móvel e meios de comunicação multinacionais devem trabalhar juntos para garantir acesso gratuito à internet ou a preços acessíveis em todas as escolas e bibliotecas de todo o mundo.

2. Compromisso com a segurança da criança ao usar a internet: A conscientização sobre potenciais perigos na internet deve se iniciar no ensino fundamental, incluindo educação sobre os direitos e responsabilidades ao usar a internet.

3. Crianças e jovens não são envolvidos na tomada de decisões: Jornais locais e nacionais devem oferecer mais espaço para publicar textos escritos por crianças, adolescentes e jovens. Cada país deve criar o seu Conselho de Juventude e Mídia.

4. A representação de crianças, adolescentes e jovens na mídia: A mídia deve adotar diretrizes éticas vigentes em matéria de comunicação sobre crianças, adolescentes e jovens, de modo a oferecer uma representação justa e equilibrada.

5. Falta de competência midiática: Educação aos meios de comunicação deve fazer parte do currículo escolar desde o ensino fundamental em todos os países.

6. Interesse comercial versus responsabilidade social: Apenas os produtos que estão relacionados com o desenvolvimento positivo de crianças, adolescentes e jovens devem ser associados com a mídia jovem.

Deve haver mais jornal/rádio/canais de TV não comerciais, financiados por fundações, governos e organizações.

\section{OS PEQUENOS CIDADÃOS E A COMUNICAÇÃO MIDIÁTICA}

Os temas levantados por adolescentes e jovens de vários países demonstram que a sociedade se movimenta e que os pequenos cidadãos estão cada vez mais participando da construção de suas imagens e afinando suas vozes para serem ouvidos. 
Contudo, resta a pergunta: até que ponto estará a sociedade adulta disposta a "ceder" para que a criança e o adolescente saiam dos seus lugares - já tradicionais - de "consumidores" e "produtos" e passem a dividir o lugar de "produtores"?

Buscando propiciar a crianças e adolescentes instrumentos que os coloquem cada vez mais no lugar de "produtores", diversos grupos da sociedade civil vêm se articulando para o desenvolvimento de projetos que democratizem a comunicação. Porém, essa luta não é recente e vem ganhando força no Brasil desde os anos de 1970, período em que os movimentos sociais iniciaram um processo de fortalecimento, tendo como base a educação e a comunicação para a transformação social.

\section{REFERÊNCIAS}

PACHECO, E. D. (org.). Televisão, criança e imaginário. São Paulo: Papirus, 1998.

BACCEGA, Maria Aparecida. Televisão e Escola: uma mediação possível? São Paulo: Senac, 2003.

BUCKINGHAM, David. Crescer na era das mídias eletrônicas. São Paulo: Loyola, 2007.

COSTA, Cristina. Educação, imagem e mídias. São Paulo: Cortez, 2005.

LINN, Susan. Honrar as crianças em tempos desonrosos: recuperando a infância da cultura da mídia comercializada. In: CAVOUKIAN, Faffi et al. Honrar a criança: Como transformar esse mundo. São Paulo: Instituto Alana, 2009.

BAKAN, Joel. Crianças e o mundo corporativo. In: CAVOUKIAN, Faffi et al. Honrar a criança: como transformar esse mundo. São Paulo: Instituto Alana, 2009 .

DEL PRIORE, Mary. História das crianças no Brasil. São Paulo: Contexto, 1999.

ROSA, Guimarães. Grande Sertão: Veredas. Rio de Janeiro: José Olympio, 1979 .

OROZCO GÓMEZ, Guillermo. Mediações e televisão pública: Adesconstrução múltipla da televidência na era da vassalagem mediática. In: RINCÓN, Omar. Televisão pública: Do consumidor ao cidadão. São Paulo: Fundação Friedrich Ebert, 2002.

MARTÍN-BARBERO, Jesús. Ensanchando territórios en comunicación/ educación. In: VALDERRAMA, Carlos. Comunicación \& Educación. Bogotá: Universidad Central, 2000. 
O mundo da comunicação e o mundo da criança • Ariane Porto Costa Rimoli

La Comunicación desde la Comunicación. Buenos Aires: Grupo Editorial Norma, 2002.

SOARES, Ismar de Oliveira. Caminhos da educomunicação na América Latina e nos Estados Unidos. In: SOARES, Ismar de Oliveira (org.). Cadernos de Educomunicação 1: Caminhos da Educomunicação. São Paulo: Editora Salesiana, 2003. 